\title{
Human 5-HT Transporter Availability Predicts Amygdala Reactivity In Vivo
}

\author{
Rebecca A. Rhodes, ${ }^{1}$ Naga Venkatesha Murthy, ${ }^{1,3}$ M. Alex Dresner, ${ }^{2}$ Sudhakar Selvaraj, ${ }^{1,4}$ Nikolaos Stavrakakis, ${ }^{1}$ \\ Syed Babar, ${ }^{5}$ Philip J. Cowen, ${ }^{4}$ and Paul M. Grasby ${ }^{1}$ \\ ${ }^{1}$ Psychiatry Group, ${ }^{2}$ Imaging Sciences Department, Medical Research Council (MRC) Clinical Sciences Centre, and ${ }^{3}$ Experimental Medicine, Psychiatry \\ Clinical Pharmaceology Discovery Medicine, GlaxoSmithKline Clinical Imaging Centre, Imperial College London, London W12 0NN, United Kingdom, \\ ${ }^{4}$ Department of Psychiatry, University of Oxford, Oxford OX3 7JX, United Kingdom, and ${ }^{5}$ Radiology Department, Hammersmith Hospital, London W12 \\ OHS, United Kingdom
}

The amygdala plays a central role in fear conditioning, emotional processing, and memory modulation. A postulated key component of the neurochemical regulation of amygdala function is the neurotransmitter 5-hydroxytryptamine (5-HT), and synaptic levels of 5-HT in the amygdala and elsewhere are critically regulated by the 5-HT transporter (5-HTT). The aim of this study was to directly examine the relationship between 5-HTT availability and amygdala activity using multimodal [positron emission tomography (PET) and functional magnetic resonance imaging (fMRI)] imaging measures in the same individuals. Healthy male volunteers who had previously undergone an $\left[{ }^{11} \mathrm{C}\right]$-3-amino-4-(2-dimethylaminomethylphenylsulfanyl)-benzonitrile $\left(\left[{ }^{11} \mathrm{C}\right]\right.$-DASB) PET scan to determine 5-HTT availability completed an fMRI emotion recognition task. $\left[{ }^{11} \mathrm{C}\right]$-DASB binding potential values were calculated for the amygdala using arterial input function and linear graphical (Logan) analysis. fMRI was performed on a 3T Philips Intera scanner, and data were analyzed using SPM2 (Wellcome Department Imaging Neuroscience, University College London). Percentage signal change during the task was extracted from the amygdala using MarsBaR (Brett et al., 2002). fMRI analysis revealed significant amygdala activation during the emotion recognition task. Region of interest analyses demonstrated a significant negative correlation between fMRI signal change in the left amygdala and 5-HTT availability in the left amygdala, with 5-HTT availability accounting for $\sim 42 \%$ of the variability in left amygdala activity. Our novel in vivo data highlight the central importance of the serotonergic system in the responsiveness of the human amygdala during emotional processing.

Key words: 5-HTT; imaging; $\left[{ }^{11} \mathrm{C}\right]-\mathrm{DASB}$; PET; fMRI; amygdala; emotion

\section{Introduction}

The amygdala plays a central role in fear conditioning, emotional processing, and memory modulation, and dysfunction of this structure has been implicated in depressive and anxiety states. Previous studies, using neuroimaging techniques, have demonstrated that patients with depressive and anxiety disorders display enhanced amygdala reactivity. For example, patients with depression show enhanced left amygdala activity in response to faces portraying negative affect (sadness/fear), compared with healthy volunteers, during functional magnetic resonance imaging (fMRI), and amygdala activity in these patients normalizes after 8 weeks of antidepressant treatment (Sheline et al., 2001; Fu et al., 2004). Additional fMRI studies have shown enhanced amygdala activity in response to negative emotional faces (sadness/fear/ anger) in adolescent and adult patients with a variety of anxiety

\footnotetext{
Received March 15, 2007; revised June 21, 2007; accepted July 5, 2007.

This work was supported by the Medical Research Council. We are grateful to Drs. Zubin Bhagwagar and Matthew Taylor for help with data acquisition and to all the volunteers who participated in the study.

Correspondence should be addressed to Prof. Paul M. Grasby, Psychiatry Group, Medical Research Council Clinical Sciences Centre, Imperial College, Hammersmith Hospital campus, Du Cane Road, London W12 0NN, UK. E-mail: paul.grasby@imperial.ac.uk.

DOI:10.1523/JNEUROSCI.1175-07.2007

Copyright $\odot 2007$ Society for Neuroscience $\quad$ 0270-6474/07/279233-05\$15.00/0
}

disorders, including generalized anxiety disorder (Thomas et al., 2001), posttraumatic stress disorder (Rauch et al., 2000), and social phobia (Stein et al., 2002; Phan et al., 2006).

A postulated key component of the neurochemical regulation of amygdala function is 5-hydroxytryptamine (5-HT; serotonin). In primates, 5-HT transporter (5-HTT)-labeled fibers densely innervate the basolateral complex, intercalated islands, and central nucleus of the amygdala: structures receiving, gating, and outputting emotionally relevant information and fear responses (O’Rourke and Fudge, 2006). Synaptic 5-HT levels in the amygdala and elsewhere are critically regulated by the 5 -HTT, and the initial mode of action of the antidepressant/anxiolytic serotoninselective reuptake inhibitors (SSRIs) is 5-HTT occupancy (Fuller, 1994). In a single intravenous infusion, or after $7 \mathrm{~d}$ of oral treatment, SSRIs attenuate the amygdala response to negative emotional faces in healthy volunteers (Del-Ben et al., 2005; Harmer et al., 2006), whereas 8 weeks of treatment with an SSRI attenuates amygdala activity in response to negative emotional faces in depressed patients (Sheline et al., 2001; Fu et al., 2004).

Additional evidence linking the 5-HTT with amygdala reactivity is provided by genetic neuroimaging studies. A functional deletion/insertion polymorphism within the 5-HTT-linked promoter region has been identified that produces short (" $\mathrm{s}$ ") or long 
("l") allelic variants (Lesch et al., 1996). The s allele has been associated with reduced 5-HTT transcription and efficiency in vitro and presumably therefore with greater synaptic 5-HT levels. In humans, the s allele has been associated with increased amygdala reactivity during emotional processing tasks (Hariri et al., 2005) and with anxiety-related traits and neuroticism in some studies (Lesch et al., 1996).

Finally, 5-HTT transgenic mice lacking the 5-HTT display increased anxiety-related behaviors in models such as the elevated plus maze and open field test (Holmes et al., 2003). Conversely, mice that overexpress the 5-HTT have been shown to display decreased anxiety-related behaviors (Jennings et al., 2006).

Given the above findings, in this study we aimed to establish whether a direct link could be made between 5-HTT availability and amygdala reactivity in healthy volunteers using a multimodal imaging approach that combined both positron emission tomography (PET) 5-HTT imaging and fMRI within the same individuals. Based on the animal and human data reviewed above, we predicted that low amygdala 5-HTT binding would be associated with enhanced amygdala reactivity.

\section{Materials and Methods}

Twenty healthy, right-handed, male volunteers (28-61 years of age; mean, 43.0 years; white, $n=17$; Asian, $n=2$; black African, $n=1$ ) participated in the study. Volunteers were free from any physical illness, had no present, or past history of, psychiatric disorder [as assessed using an abridged nonpatient version of the Structured Clinical Interview for Diagnostic and Statistical Manual of Mental Disorders (Fourth Edition)], were not currently taking any medications, and had never been treated with psychotropic medication. Ethical approval for the study was obtained from the Hammersmith, Queen Charlotte's, and Chelsea Hospitals Research Ethics committee, and all participants gave written, informed consent.

PET acquisition. All PET scans were performed at the Cyclotron Unit, Hammersmith Hospital (London, UK). PET scans were performed on an ECAT HR ++ scanner (CTI, Knoxville, TN) with an axial field of view (FOV) of $23.4 \mathrm{~cm}$ and 95 reconstructed transaxial image planes. The radioligands currently most widely used for the in vivo quantification of 5-HTT availability in human PET are $\left[{ }^{11} \mathrm{C}\right]-\mathrm{McN} 5652\left(\left[{ }^{11} \mathrm{C}\right]-(+)-6 \beta-(4-\right.$ methylthiophenyl )-1,2,3,5,6 $\alpha, 10 \beta$-hexahydropyrrolo [2,1-a] isoquinoline) and $\left[{ }^{11} \mathrm{C}\right]$-3-amino-4-(2-dimethylaminomethylphenylsulfanyl)-benzonitrile $\left(\left[{ }^{11} \mathrm{C}\right]\right.$-DASB $)$. Because of the higher ratio of specific to nonspecific binding, $\left[{ }^{11} \mathrm{C}\right]$-DASB was selected as the PET radioligand for our imaging study (Frankle et al., 2004). [ $\left.{ }^{11} \mathrm{C}\right]$-DASB was synthesized as described previously (Wilson et al., 2000). [ $\left.{ }^{11} \mathrm{C}\right]$-DASB scanning was as described by Bhagwagar et al. (2007). The injected radioactivity dose was $503 \pm 62$ $\mathrm{MBq}$ (range, 308-555 MBq). The radiochemical purity of the injected $\left[{ }^{11} \mathrm{C}\right]-\mathrm{DASB}$ was high (range, $\left.96-100 \%\right)$. The injected mass of cold DASB was $4 \pm 2.8 \mu \mathrm{g}$ (range, $1.3-12.2 \mu \mathrm{g}$ ). The specific activity was high: $51,651 \pm 28,833 \mathrm{MBq} \cdot \mu \mathrm{mol}^{-1}$.

Region of interest definition in PET analysis. Participants' structural T1-weighted MRI scans were resliced to a voxel size of $1 \times 1 \times 1 \mathrm{~mm}$ and coregistered to the individual summated PET images using statistical parametric mapping (SPM2; Wellcome Department of Neurology, University College London, London, UK). Bilateral amygdala and cerebellum (reference region) regions of interest (ROIs) were defined on the coregistered MRI using a probabilistic brain atlas template (Hammers et al., 2003). The cerebellum has previously been characterized as a region with low concentration of 5-HTT. The atlas was normalized to the coregistered individual MRI scans with deformation parameters obtained from the normalization of a standard Montreal Neurological Institute (MNI) T1 template (SPM2). The normalized brain atlas was resliced to the individual PET space and segmented to obtain data from gray matter only. Dynamic PET scans were then sampled by applying the individual amygdala object map. The size of the atlas-based amygdala regions were $2097 \mathrm{~mm}^{3}$ and $1983 \mathrm{~mm}^{3}$ for the left and right amygdala, respectively.
The dorsal raphe region was manually defined as a fixed-size region (900 $\mathrm{mm}^{3}$ ) on the summed dynamic PET images of each individual.

Quantification of DASB binding. The graphical analysis of reversible radioligand binding using the plasma input function (Logan et al., 1990) has been reported to provide regional estimates of the total volume of distribution $(V D)$ with excellent reproducibility and highly correlated with those obtained with a one-tissue and two-tissue compartment model (Frankle et al., 2006). This method was therefore chosen to obtain regional $V D$ estimates from the slope of the linear part of the plot. With the definition of binding potential $(B P)$ introduced by Mintun et al. (1984), and $f_{2}$ as the free fraction of radioligand in tissue, estimates of binding potential in a target region with specific binding can be obtained from the estimated $V D$ in that region and the estimated $V D$ in a reference region without specific binding where $f_{2} \times B P=\left(V D_{\text {target region }} /\right.$ $\left.V D_{\text {reference region }}\right)-1$ (with $f_{2} \times B P$ being our measure of 5-HTT availability).

MRI acquisition. Functional MRI scanning was performed on a 3 tesla Philips (Best, The Netherlands) Intera scanner. Functional T2*-weighted images were acquired using gradient-echo echoplanar imaging, with an automated higher-order shim procedure [SENSE factor 2; echo time (TE), $30 \mathrm{~ms}$; repetition time (TR), $3000 \mathrm{~ms}$; flip angle, $90^{\circ}$; FOV, $280 \mathrm{~mm}$; voxel dimensions, $2.2 \times 2.2 \times 2.75 \mathrm{~mm}$ ]. Images were acquired in 48 contiguous $2.75 \mathrm{~mm}$ axial slices per brain volume. Functional images were acquired during a single run of $8 \mathrm{~min}$ ( 160 volumes acquired in total, with the first five volumes being discarded to account for T1 equilibration effects). A high-resolution T1-weighted turbo field echo structural scan was also acquired for each participant for normalization purposes (TE, $4.6 \mathrm{~ms}$; TR, $9.7 \mathrm{~ms}$; flip angle, $8^{\circ}$; FOV, $240 \mathrm{~mm}$; voxel dimensions, $0.94 \times 0.94 \times 1.2 \mathrm{~mm}$ ). The mean \pm SEM time interval between PET and fMRI data acquisition was $60.0 \pm 4.13$ weeks.

fMRI experimental paradigm. During fMRI scanning, participants completed a block design emotional expression recognition paradigm [based on Hariri et al., (2005)]. Briefly, participants viewed faces displaying angry or fearful emotions (Ekman and Friesen, 1976) and performed an emotion-matching task that required the emotion displayed on a target face (presented at the top of the screen) to be matched with the emotion displayed by one of two test faces (presented below the target face). A sensorimotor control condition required participants to perform a shape-matching task (a target shape at the top of the screen had to be matched to one of two test shapes). Six blocks of emotion matching and six blocks of shape matching were presented in a pseudorandom order, interspersed with three blocks of a low-level rest condition. Each block lasted $30 \mathrm{~s}$, and faces/shapes were presented for $5 \mathrm{~s}$ (six presentations per block). Five volumes (15 s) were acquired at the end of the paradigm while the participant viewed a fixation cross to capture the end of the hemodynamic response. Total experimental time was $7 \mathrm{~min}$ and $45 \mathrm{~s}$.

fMRI analysis. Functional image analysis was performed using SPM2. Preprocessing steps before statistical analysis included slice time correction, motion correction, and spatial normalization to a standard template in MNI space (using the T1 SPM template and resulting in voxels of $2 \times 2 \times 2 \mathrm{~mm}$ ). Normalized images were smoothed with an $8 \mathrm{~mm}$ full-width at half-maximum isotropic Gaussian kernel. Task conditions (faces, shapes, and rest) were modeled using the standard hemodynamic response function. To correct for signal changes caused by head movement, the six realignment parameters were included in the design matrix. A temporal high-pass filter (cutoff, $256 \mathrm{~s}$ ) was applied, and temporal autocorrelation was modeled as an $\mathrm{AR}(1)$ process. Individual participant images were analyzed at the first level to produce estimates for the contrast of interest (emotional faces vs shapes), and contrast images were then analyzed at the second level in a group random-effects analysis using a one-sample $t$ test (threshold significance set at $p<0.001$, uncorrected). For analysis of activation within the amygdala, a small volume correction (SVC) for multiple comparisons was used [familywise error (FWE) corrected]. The search volume was defined by an image of the left or right amygdala, as defined using a probabilistic atlas in MNI space based on 20 healthy volunteers (Hammers et al., 2003). Estimates of percentage signal change during viewing of emotional faces (from the emotional faces vs shapes contrast) were also extracted from the amygdala and lingual gyrus for each participant using MarsBaR [Marseille boîte à région d'intérêt 
(Brett et al., 2002)] and ROIs defined from the probabilistic atlas. The lingual gyrus was selected as a control region because it was significantly and robustly activated by the faces task and could be used to assess the specificity of the relationship between 5-HTT availability and blood oxygenation level-dependent (BOLD) signal change. fMRI signal change measures were correlated with 5-HTT binding potentials using SPSS (SPSS, Chicago, IL).

\section{Results}

Mean \pm SEM $\left[{ }^{11} \mathrm{C}\right]$-DASB BPs for the left and right amygdala and the dorsal raphe were $1.79 \pm 0.09,1.74 \pm 0.10$, and $4.11 \pm$ 0.25 , respectively. Mean \pm SEM VDs for these regions were as follows: left amygdala, $28.9 \pm 1.14$; right amygdala, $28.3 \pm 0.90$; dorsal raphe, $52.7 \pm 2.70$. Age did not correlate with 5-HTT BP in our sample of participants $(r=-0.05, p=0.85$ and $r=-0.11$, $p=0.65$ for left and right amygdala, respectively; $r=-0.13, p=$ 0.59 for dorsal raphe). The emotional faces versus shapematching contrast revealed activation of both the left and right amygdala (Fig. 1) ( $p<0.001$, uncorrected). Importantly, activation in the amygdala remained significant after SVC for multiple comparisons (left amygdala, MNI coordinates, $-22,-6,-16$; $z=3.87 ; p=0.006$, FWE corrected; right amygdala, MNI coordinates, 22, $-6,-14 ; z=3.09 ; p=0.05$, FWE corrected). Mean \pm SEM percentage signal change in the left and right amygdala was $0.10 \pm 0.04$ and $0.10 \pm 0.05$, respectively. Age did not correlate with either left or right amygdala mean percentage signal change ( $r=-0.14, p=0.55$ and $r=0.19, p=0.43$, respectively).

5-HTT availability is inversely related to amygdala reactivity As predicted, within the left amygdala 5-HTT availability negatively correlated with percentage signal change during viewing of emotional faces compared with shapes $\left(r=-0.65 ; r^{2}=0.42 ; p=\right.$ 0.002) (Fig. 2). 5-HTT availability in the left amygdala therefore accounted for $\sim 42 \%$ of the variability in left amygdala reactivity. This relationship was also observed when correlating left amygdala $V D$ with left amygdala reactivity $(r=-0.58 ; p=0.007)$ but not when correlating cerebellar $V D$ with left amygdala reactivity $(r=-0.11 ; p=0.63)$. This ipsilateral relationship between 5-HTT availability and amygdala reactivity was not evident in the right amygdala. However, left amygdala 5-HTT availability also negatively correlated with percentage signal change in the right amygdala $\left(r=-0.46 ; r^{2}=0.21 ; p=0.04\right)$. As evident from Figure 2, some of the participants had negative fMRI signal change values; i.e., amygdala reactivity was greater to the shapematching condition than to the face-matching condition. When limiting the correlation analysis to only those participants with positive signal change, left amygdala reactivity still negatively correlated with left amygdala 5 -HTT availability $(n=13 ; r=-0.50$; $p=0.04$, one-tailed).

\section{Specificity of the relationship between amygdala 5-HTT availability and fMRI activation}

To examine the functional specificity of the relationship between amygdala 5-HTT availability and BOLD signal change, amygdala 5-HTT binding was also correlated with percentage signal change in the occipital lobe (lingual gyrus). There was no relationship between either left or right amygdala 5-HTT availability and fMRI percentage signal change in the left lingual gyrus $(r=$ $-0.07, p=0.79$ and $r=0.37, p=0.11$, respectively, for left and right amygdala 5-HTT availability) (Fig. 3 ) or the right lingual gyrus $(r=0.05, p=0.82$ and $r=0.10, p=0.68$, respectively, for left and right amygdala 5-HTT availability).

In addition, to examine the anatomical specificity of the rela-
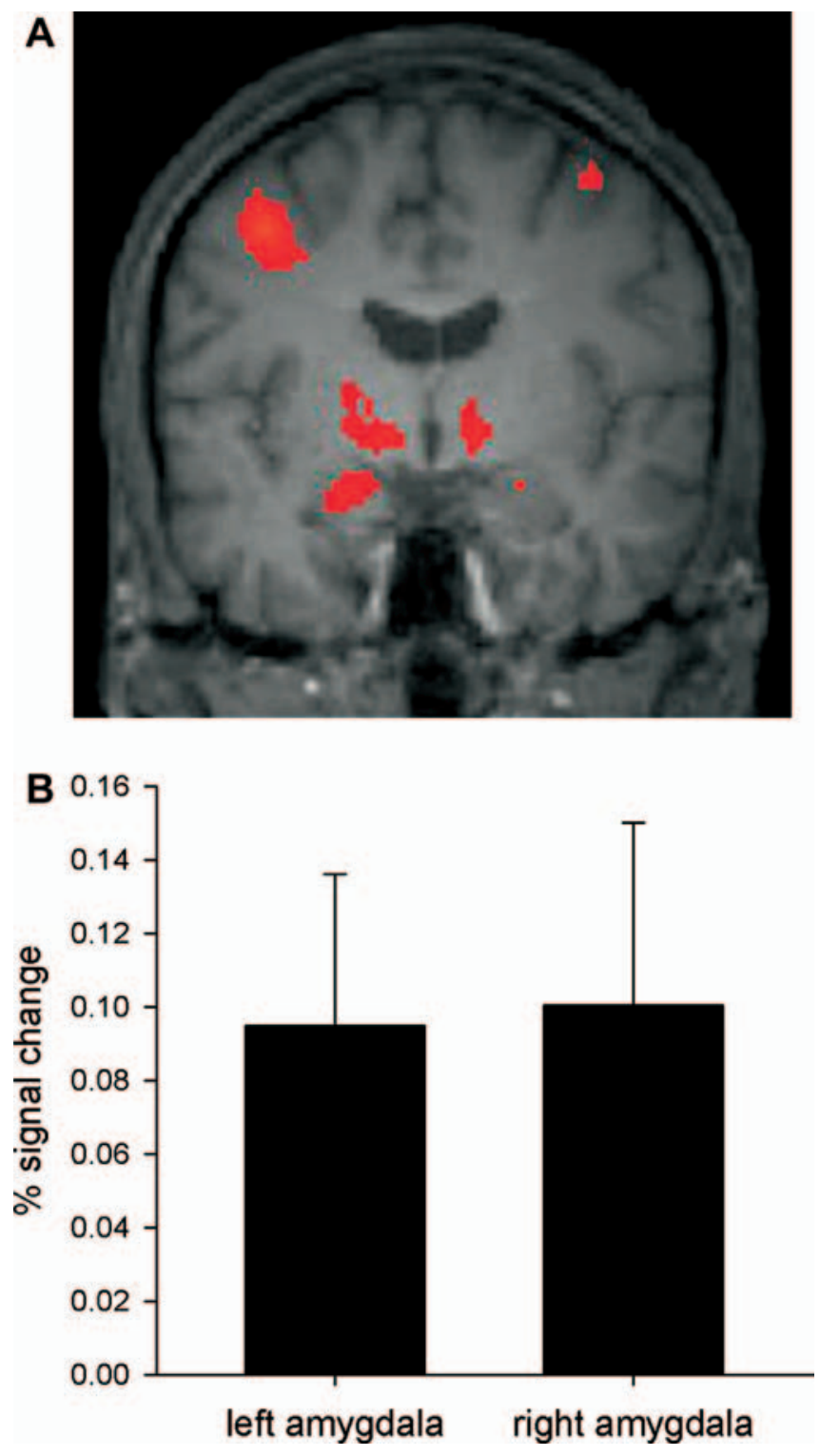

Figure 1. Amygdala reactivity during the emotional faces task (emotional faces vs shapes contrast). $\boldsymbol{A}$, Statistical parametric map from the group random-effects analysis displaying amygdala activation (whole-brain analysis presented at $p<0.001$, uncorrected). Data are overlaid on a mean structural image of the 20 participants (left is left). MNI coordinates for the maximal voxel in the left and right amygdala are, respectively, $x=-22, y=-6, z=-16$ (cluster size, 30 voxels; $z$ score $=3.87$ ) and $x=22, y=-6, z=-14$ (cluster size, 1 voxel; $z$ score $=3.09)$. $\boldsymbol{B}$, Percentage signal change in the left and right amygdala as measured with MarsBaR (mean \pm SEM).

tionship, 5-HTT availability in the dorsal raphe was correlated with amygdala percentage signal change during the fMRI task; dorsal raphe 5-HTT availability did not correlate with either left $(r=-0.21 ; p=0.38)$ or right $(r=-0.26 ; p=0.28)$ amygdala fMRI signal change.

\section{Discussion}

As hypothesized, we found a significant inverse relationship between left amygdala 5-HTT availability and left amygdala reactivity in healthy participants, as assessed through combined PET and fMRI. To our knowledge, this is the first time this relationship has been demonstrated in humans. Thus, participants with reduced amygdala 5-HTT availability showed enhanced amygdala reactivity, a finding in line with predictions from both hu- 


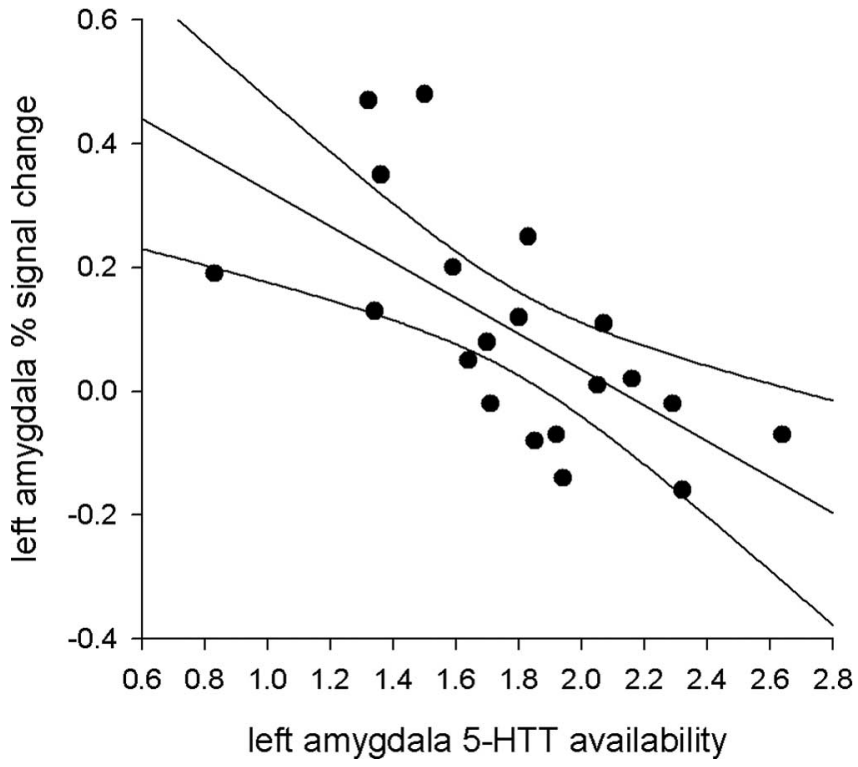

Figure 2. Scatterplot of left amygdala 5-HTT availability and left amygdala fMRI signal change. ROls were defined using a probabilistic atlas based on 20 healthy participants. Ninetyfive percent confidence limits are included with the regression line. Left amygdala $\left[{ }^{11} \mathrm{C}\right]-\mathrm{DASB}$ binding negatively correlated with left amygdala signal change during the emotional face processing task $(r=-0.65 ; p=0.002)$.

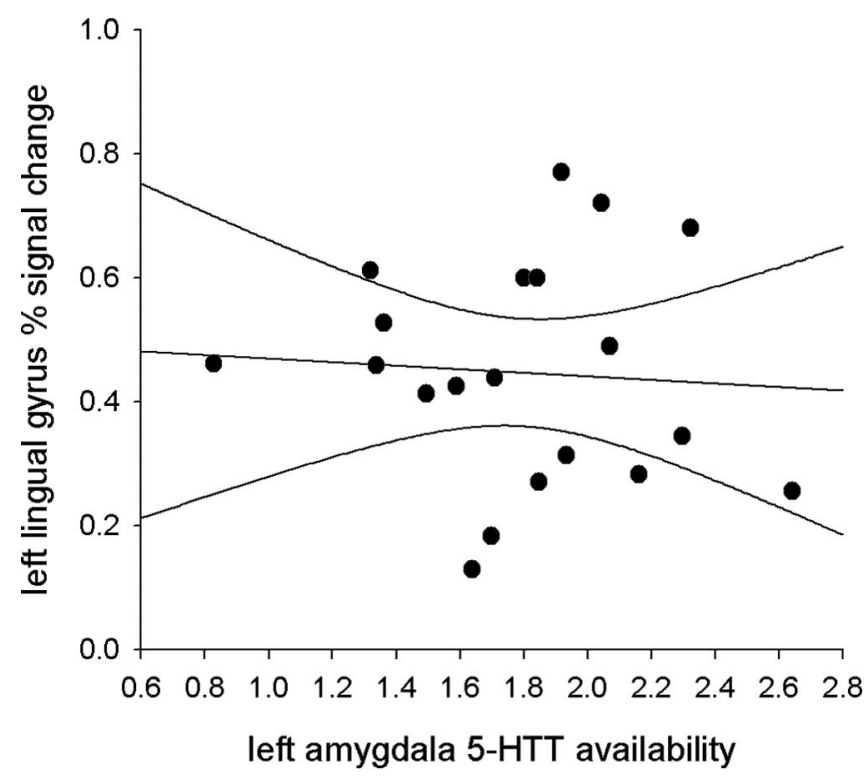

Figure 3. Scatterplot of left amygdala $\left[{ }^{11} \mathrm{C}\right]-\mathrm{DASB}$ binding and left lingual gyrus fMRI signal change. ROls were defined using a probabilistic atlas based on 20 healthy participants. Ninetyfive percent confidence limits are included with the regression line. There was no significant correlation between left amygdala $\left[{ }^{11} \mathrm{C}\right]-\mathrm{DASB}$ binding and left lingual gyrus signal change during the emotional face processing task $(r=-0.07 ; p=0.79)$.

man genetic association and transgenic mice studies of the 5-HTT (see Introduction).

The most significant relationship we observed was between left amygdala 5-HTT availability and fMRI percentage signal change in the left amygdala. Although left amygdala 5-HTT availability negatively correlated with right amygdala signal change, there was no relationship between right 5-HTT availability and right amygdala signal change. This could potentially be a result of the variability of the fMRI response within the right amygdala. Certainly, amygdala activation in response to faces displaying negative emotions such as fear is a consistent finding in the literature (for review, see Adolphs, 2002), although there is less consensus as to the laterality of this finding, with studies reporting both unilateral amygdala activation and bilateral amygdala activation in response to emotional faces (for review, see Baas et al., 2004).

A limitation of the current study is that only male participants were studied. Future studies will have to assess whether gender has an effect on the relationship between 5-HTT availability and amygdala reactivity reported here. Although previous studies have not found associations between 5-HTT availability and gender (Meyer et al., 2004), effects of gender on laterality and strength of amygdala activation in response to emotional material have been reported (Killgore and Yurgelun-Todd, 2001; Wrase et al., 2003).

An additional limitation of this study is that although the number of participants is reasonable for a combined PET/fMRI experiment, it is low for a comprehensive examination of the influence of the 5-HTT-linked promoter region s/l polymorphism on either 5-HTT availability or amygdala reactivity. However, in a subsample of the volunteers studied $(n=13)$, this polymorphism did not influence either $\left[{ }^{11} \mathrm{C}\right]$-DASB BP or fMRI percentage signal change in the amygdala (data not shown).

$\left[{ }^{11} \mathrm{C}\right]$-DASB BP values in this study were calculated using arterial input function and linear graphical (Logan) analysis. This method enabled correlation of amygdala $V D$ with amygdala reactivity (without the confound of changes of cerebellar $V D$ ), which confirmed that $\left[{ }^{11} \mathrm{C}\right]-\mathrm{DASB} B P$ values in the amygdala were driving the correlation with amygdala reactivity. Recent studies using $\left[{ }^{11} \mathrm{C}\right]$-DASB have reported comparable $B P$ values to those in this study (Ginovart et al., 2001). Although it would have been preferable to perform the PET and fMRI scanning on the same day, the time interval between acquisition of the two types of scan data is unlikely to have influenced the results. Unpublished observations of $\left[{ }^{11} \mathrm{C}\right]$-DASB test-retest measures in our unit (and elsewhere) are high, and indicate that $\left[{ }^{11} \mathrm{C}\right]-\mathrm{DASB}$ binding is stable when measured over weeks to months. In addition, a previous study reported an average age-related change in 5 -HTT availability in the thalamus and midbrain of $\sim 10 \%$ per decade (Yamamoto et al., 2002). We therefore consider that the binding potential measures in this study would be stable over the time scale of the experiment. With regard to amygdala reactivity, Johnstone et al. (2005) have examined the stability of amygdala BOLD responses to fearful faces, and report moderate-to-high stability of the left amygdala response.

Facial emotional processing tasks have also been used to investigate the effect of serotonergic modulation on the neural response to viewing faces displaying negative affect. Studies have found that both acute (Del-Ben et al., 2005) and subchronic (Harmer et al., 2006) treatment with an SSRI attenuates the neural response of the amygdala to faces displaying negative affect. However, our data showing a negative correlation between amygdala 5-HTT availability and fMRI signal might predict that an SSRI, by reducing 5-HTT availability via occupancy, would enhance amygdala reactivity. The comparability of these observations is, however, questionable. Specifically, systemic SSRI treatment will obviously affect not only amygdala 5-HTT availability, but also 5-HTT availability in other brain structures that modulate amygdala reactivity (e.g., prefrontal cortex). The role of a distributed corticolimbic circuitry, including ventromedial and orbitofrontal cortices, in emotional processing has recently been emphasized (for review, see Hariri and Fisher, 2007), and variations in 5-HT neurotransmission within any aspect of this circuitry could 
influence the emotional reactivity of the amygdala. Additionally, a change of 5-HTT availability within an individual, as a result of SSRI occupancy, may not be functionally equivalent to a difference of baseline 5-HTT availability between individuals.

A recent report from Fisher et al. (2006) demonstrated that another component of 5-HT neurotransmission, the raphe $5-\mathrm{HT}_{1 \mathrm{~A}}$ autoreceptor, also influences amygdala reactivity. However, they reported a significant inverse relationship between $5-\mathrm{HT}_{1 \mathrm{~A}}$ binding in the dorsal raphe and bilateral amygdala reactivity, with the effect being stronger in the right amygdala. That is, increased raphe autoreceptor $5-\mathrm{HT}_{1 \mathrm{~A}}$ binding (which is inhibitory to 5-HT synthesis and cell firing), and therefore presumably decreased synaptic 5-HT within the amygdala, was associated with decreased amygdala reactivity. This result complements the findings presented here, in which increased amygdala 5-HTT availability (presumably leading to decreased synaptic 5-HT) was associated with reduced amygdala activation. In conclusion, our data, together with those of Fisher et al. (2006), clearly highlight the central importance of the serotonergic system in the responsiveness of the human amygdala during emotional processing.

\section{References}

Adolphs R (2002) Neural systems for recognizing emotion. Curr Opin Neurobiol 12:169-177.

Baas D, Aleman A, Kahn RS (2004) Lateralization of amygdala activation: a systematic review of functional neuroimaging studies. Brain Res Brain Res Rev 45:96-103.

Bhagwagar, Z, Murthy NV, Selvaraj S, Hinz R, Taylor MJ, Fancy S, Grasby PM, Cowen PJ (2007) 5-HTT binding does not distinguish recovered depressed patients from controls: a positron emission tomography study with $\left[{ }^{11} \mathrm{C}\right]-D A S B$. Am J Psychiatry, in press.

Brett M, Anton J, Valabregue R, Poline J (2002) Region of interest analysis using an SPM toolbox [abstract]. Paper presented at the 8th International Conference on Functional Mapping of the Human Brain, Sendai, Japan.

Del-Ben CM, Deakin JF, McKie S, Delvai NA, Williams SR, Elliott R, Dolan M, Anderson IM (2005) The effect of citalopram pretreatment on neuronal responses to neuropsychological tasks in normal volunteers: an fMRI study. Neuropsychopharmacology 30:1724-1734.

Ekman P, Friesen WV (1976) Pictures of facial affect. Palo Alto, CA: Consulting Psychologists.

Fisher PM, Meltzer CC, Ziolko SK, Price JC, Hariri AR (2006) Capacity for $5-\mathrm{HT}_{1 \mathrm{~A}}$-mediated autoregulation predicts amygdala reactivity. Nat Neurosci 9:1362-1363.

Frankle WG, Huang Y, Hwang DR, Talbot PS, Slifstein M, Van Heertum R, Abi-Dargham A, Laruelle M (2004) Comparative evaluation of serotonin transporter radioligands $\left[{ }^{11} \mathrm{C}\right]-\mathrm{DASB}$ and $\left[{ }^{11} \mathrm{C}\right]-\mathrm{McN} 5652$ in healthy humans. J Nucl Med 45:682-694.

Frankle WG, Slifstein M, Gunn RN, Huang Y, Hwang DR, Darr EA, Narendran R, Abi-Dargham A, Laruelle M (2006) Estimation of serotonin transporter parameters with $\left[{ }^{11} \mathrm{C}\right]-\mathrm{DASB}$ in healthy humans: reproducibility and comparison of methods. J Nucl Med 47:815-826.

Fu CHY, Williams SCR, Cleare AJ, Brammer MJ, Walsh ND, Kim J, Andrew CM, Pich EM, Williams PM, Reed LJ, Mitterschiffthaler MT, Suckling J, Bullmore ET (2004) Attenuation of the neural response to sad faces in major depression by antidepressant treatment. Arch Gen Psychiatry 61:877-889.

Fuller RW (1994) Uptake inhibitors increase extracellular serotonin concentration measured by brain microdialysis. Life Sci 55:163-167.

Ginovart N, Wilson AA, Meyer JH, Hussey D, Houle S (2001) Positron emission tomography quantification of $\left[{ }^{11} \mathrm{C}\right]$-DASB binding to the human serotonin transporter: modeling strategies. J Cereb Blood Flow Metab 21:1342-1353.

Hammers A, Allom R, Koepp MJ, Free SL, Myers R, Lemieux L, Mitchell TN, Brooks DJ, Duncan JS (2003) Three-dimensional maximum probability atlas of the human brain, with particular reference to the temporal lobe. Hum Brain Mapp 19:224-247.

Hariri AR, Fisher PM (2007) Regulation of corticolimbic reactivity via the
5-HT1A autoreceptor in the pathophysiology and treatment of depression. Future Neurol 2:121-124.

Hariri AR, Drabant EM, Munoz KE, Kolachana BS, Mattay VS, Egan MF, Weinberger DR (2005) A susceptibility gene for affective disorders and the response of the human amygdala. Arch Gen Psychiatry 62:146-152.

Harmer CJ, Mackay CE, Reid CB, Cowen PJ, Goodwin GM (2006) Antidepressant drug treatment modifies the neural processing of nonconscious threat cues. Biol Psychiatry 59:816-820.

Holmes A, Yang RJ, Lesch KP, Crawley JN, Murphy DL (2003) Mice lacking the serotonin transporter exhibit $5-\mathrm{HT}_{1 \mathrm{~A}}$ receptor-mediated abnormalities in tests for anxiety-like behaviour. Neuropsychopharmacology 28:2077-2088.

Jennings KA, Loder MK, Sheward WJ, Pei Q, Deacon RM, Benson MA, Olverman HJ, Hastie ND, Harmar AJ, Shen S, Sharp T (2006) Increased expression of the 5-HT transporter confers a low-anxiety phenotype linked to decreased 5-HT transmission. J Neurosci 26:8955-8964.

Johnstone T, Somerville LH, Alexander AL, Oakes TR, Davidson RJ, Kalin NH, Whalen PJ (2005) Stability of amygdala BOLD response to fearful faces over multiple scan sessions. NeuroImage 25:1112-1123.

Killgore WDS, Yurgelun-Todd DA (2001) Sex differences in amygdala activation during the perception of facial affect. NeuroReport 12:2543-2547.

Lesch KP, Bengel D, Heils A, Sabol SZ, Greenberg BD, Petri S, Benjamin J, Muller CR, Hamer DH, Murphy DL (1996) Association of anxietyrelated traits with a polymorphism in the serotonin transporter gene regulatory region. Science 274:1527-1531.

Logan J, Fowler JS, Volkow ND, Wolf AP, Dewey SL, Schlyer DJ, MacGregor RR, Hitzemann R, Bendriem B, Gatley SJ (1990) Graphical analysis of reversible radioligand binding from time-activity measurements applied to [N-11C-methyl]-(-)-cocaine PET studies in human subjects. J Cereb Blood Flow Metab 10:740-747.

Meyer JH, Houle S, Sagrati S, Carella A, Hussey DF, Ginovart N, Goulding V, Kennedy J, Wilson AA (2004) Brain serotonin transporter binding potential measured with carbon 11-labeled DASB positron emission tomography: effects of major depressive episodes and severity of dysfunctional attitudes. Arch Gen Psychiatry 61:1271-1279.

Mintun MA, Raichle ME, Kilbourn MR, Wooten GF, Welch MJ (1984) A quantitative model for the in vivo assessment of drug binding sites with positron emission tomography. Ann Neurol 15:217-227.

O'Rourke H, Fudge JL (2006) Distribution of serotonin transporter labeled fibers in amygdaloid subregions: implications for mood disorders. Biol Psychiatry 60:479-490.

Phan KL, Fitzgerald DA, Nathan PJ, Tancer ME (2006) Association between amygdala hyperactivity to harsh faces and severity of social anxiety in generalized social phobia. Biol Psychiatry 59:424-429.

Rauch SL, Whalen PJ, Shin LM, McInerney SC, Macklin ML, Lasko NB, Orr SP, Pitman K (2000) Exaggerated amygdala response to masked facial stimuli in posttraumatic stress disorder. Biol Psychiatry 47:769-776.

Sheline YI, Barch DM, Donnelly JM, Ollinger JM, Snyder AZ, Mintun MA (2001) Increased amygdala response to masked emotional faces in depressed subjects resolves with antidepressant treatment: an fMRI study. Biol Psychiatry 50:651-658.

Stein MB, Goldin PR, Sareen J, Zorrilla LTE, Brown GG (2002) Increased amygdala activation to angry and contemptuous faces in generalized social phobia. Arch Gen Psychiatry 59:1027-1034.

Thomas KM, Drevets WC, Dahl RE, Ryan ND, Birmaher B, Eccard CH, Axelson D, Whalen PJ, Casey BJ (2001) Amygdala response to fearful faces in anxious and depressed children. Arch Gen Psychiatry 58:1057-1063.

Wilson AA, Ginovart N, Schmidt M, Meyer JH, Threlkeld PG, Houle S (2000) Novel radiotracers for imaging the serotonin transporter by positron emission tomography: synthesis, radiosynthesis, and in vivo and ex vivo evaluation of 11C-labeled 2-(phenylthio)araalkylamines. J Med Chem 43:3103-3110.

Wrase J, Klein S, Gruesser SM, Hermann D, Flor H, Mann K, Braus DF, Heinz A (2003) Gender differences in the processing of standardized emotional visual stimuli in humans: a functional magnetic resonance imaging study. Neurosci Lett 348:41-45.

Yamamoto M, Suhara T, Okubo Y, Ichimiya T, Sudo Y, Inoue M, Takano A, Yasuno F, Yoshikawa K, Tanada S (2002) Age-related decline of serotonin transporters in living human brain of healthy males. Life Sci 71:751757. 